\title{
EXPERIMENTAL INVESTIGATION OF AN AUTOMOTIVE MAGNETORHEOLOGICAL SHOCK ABSORBER
}

\author{
Łukasz JASTRZĘBSKI*, Bogdan SAPIŃSKI ${ }^{\star}$ \\ "Mechanical Engineering and Robotics, Department of Process Control, AGH University of Science and Technology, \\ al. Mickiewicza 30, 30-059 Kraków, Poland \\ lukasz.jastrzebski83@gmail.com, deep@agh.edu.pl
}

received 24 May 2016, revised 2 October 2017, accepted 6 October 2017

\begin{abstract}
The study summarises the experimental examination of an automotive magnetorheological (MR) shock absorber under electrical and mechanical excitations, investigates its current and force responses and the energy dissipation in the system. The aim of experiments was to acquire measurement data that allows in next step of the research program to engineer an energy harvesting device for the absorber. The work covers basic technical data of the absorber, description of the experimental set-up, scenario of testing program and test results of the device. Of particular importance is the influence the operating current, piston displacement amplitude and piston velocity have on the absorber's response.
\end{abstract}

Key words: MR Shock Absorber, Vibration, Current Response, Force Response, Dissipated Energy

\section{INTRODUCTION}

The property of magnetorheological (MR) fluids manifesting itself by changes in the material's apparent viscosity when exposed to a magnetic field has made them attractive for use in many applications, including the automotive industry (Choi and Sung, 2008; Choi and Han, 2012; El-Kafafy et al., 2012; Sung and Choi, 2009). One of the most spectacular application in this field was the semiactive vehicle suspension system that utilized MR dampers for realtime control of the motion of a vehicle. Presently MR dampers are installed in various types of vehicles: passenger cars and sports vehicles, to improve the ride comfort by controlling undesired vibrations. The principal design parameters of MR dampers intended for vehicle suspension application are the magnetic gap in which MR fluid flows between upper and lower chambers, the radius of the piston, and bobbin structures involving the coil turns. By choosing appropriate values of these principal design parameters, successful vibration control can be implemented. Extensive research efforts have brought major headway in response time improvements, higher dynamic range, effective control and better response at low body velocities of MR dampers (Gołdasz and Dzierżek, 2016; Koo et al., 2006; Sapiński and Rosół, 2007; Strecker et al., 2015 a, b, c; Wu et al., 2011).

The aspect of MR damper applications that has received a great deal of attention recently is energy harvesting (Sapiński, 2014; Wang and Bai, 2013; Xinchun et al., 2015) whereby an MR damper in a typical confguration is driven by energy harvested from a vehicle while in motion. The mechanical energy that otherwise would be unused and lost through heat is converted into electricity and used for monitoring of an associated MR damper output.

The object of this study is the Magnetic Ride absorber used in cars of series Audi TT Quatro. The aim of the work is to evaluate the absorber's performance through experiments. The current responses of the device are determined when the amplifier is operated in the voltage and current mode, the force responses are determined when the device is subjected to a particular excitation from a range of displacements inputs. The obtained experimental results allow a special harvester to be designed such that the tested absorber can be energized (controlled) when implemented in a laboratory model of an automotive semi-active suspension system with energy harvesting capability

\section{SPECIFICATION OF THE SHOCK ABSORBER}

The structure of the investigated MR shock absorber is shown in Fig. 1. The device has a typical configuration of mono-tube flowmode damper with an annular gap (Gołdasz and Sapiński, 2015). Geometrical parameters of the absorber are: piston stroke $178 \mathrm{~mm}$, outer diameter of the cylinder $50 \mathrm{~mm}$, the length with the piston in compression position $381 \mathrm{~mm}$, the length with the piston in rebound position $559 \mathrm{~mm}$. The cylinder is filled with $277 \mathrm{~cm}^{3}$ of MR fluid. The shock absorber comprises an accumulator $65 \mathrm{~cm}^{3}$ in volume, filled with nitrogen. The maximal current in the control coil should not exceed $5 \mathrm{~A}$. The device ought to be operated in the temperatures range $(-30,100){ }^{\circ} \mathrm{C}$. The absorber's force response in the stroke center position is $335 \mathrm{~N}$.

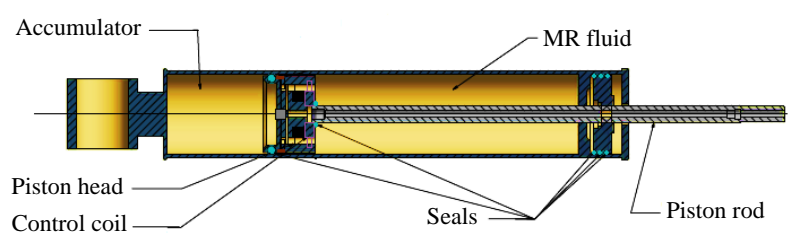

Fig. 1. Schematic diagram of the shock absorber 


\section{TESTING PROGRAM}

The main purpose was to determine the current response in the absorber's control coil circuit to the applied step voltage excitations and the force response under the triangular and sine inputs (piston displacements).

Current responses were registered in the measurement system shown schematically in Fig. 2. The system comprises a power supply, an amplifier, a AD/DA board installed in a PC. To ensure the correct operation of the amplifier (Sapiński et al., 2012), it needs a symmetrical DC voltage supply $\pm 12 \mathrm{~V}$. The amplifier can operate either in voltage mode or current mode (in this case with an integrated PID controller). The amplifier ensures that the maximal current supplying the coil should not exceed $7 \mathrm{~A}$ (the non-inverting operational amplifier OPA549 was used here). Integrated internal circuits in the amplifier, based on AD629, AD8622 operational amplifiers and $10 \mathrm{~m} \Omega$ resistor, permit the measurements of voltage $u$ and current $i$. Registered signals are converted into voltage signals in the range $\pm 10 \mathrm{~V}$. Input voltage or current in an amplifier is controlled via an analogue input to which voltage $u_{c}$ is supplied, in the range $\pm 10 \mathrm{~V}$. The AD/DA board type RT-DAC 4 PCI [17] interacting with MATLAB/Simulink is used for generation of command signal $U_{c}$ and for voltage and current measurements.

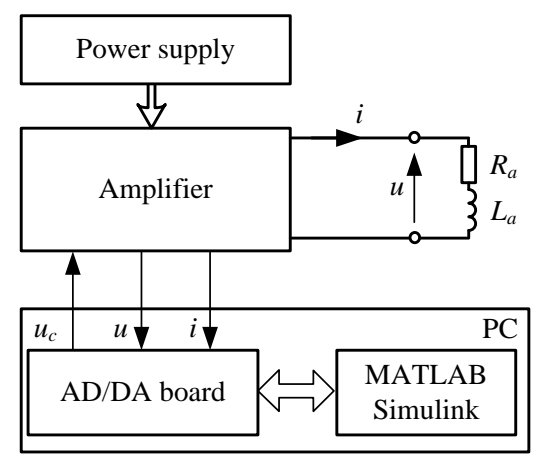

Fig. 2. Schematic diagram of the measurement system

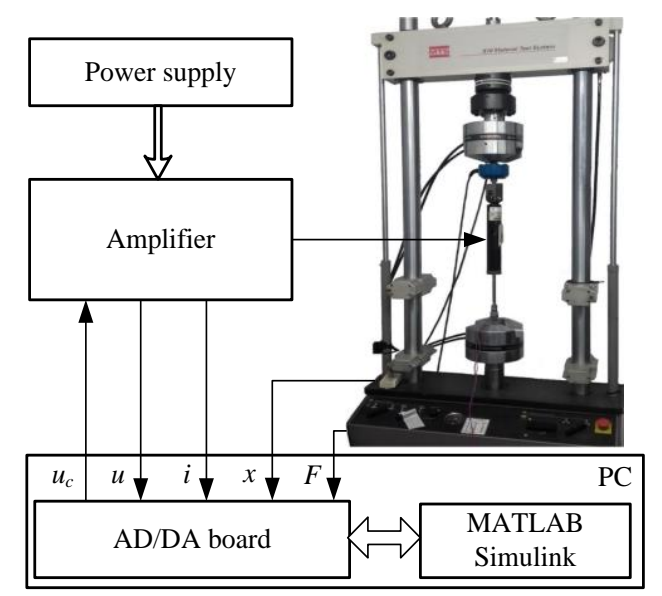

Fig. 3. Schematic diagram of the testing set-up

Force responses were registered using the MTS 810 testing machine-based set-up (see Fig. 3) and the components of the measurement system shown in Fig. 2. To an AD/DA board two voltage signals are supplied (in the range $\pm 10 \mathrm{~V}$ ) corresponding to the piston displacement $x$ and force $F$ measured on the MTS tester. The maximal rate of the piston motion implemented on the MTS tester was $150 \mathrm{~mm} / \mathrm{s}$. The measurement range of the force sensor was $\pm 5 \mathrm{kN}$. Registered signals were sampled with the frequency $1 \mathrm{kHz}$ and converted into voltage signals in the range $\pm 10 \mathrm{~V}$.

The testing procedure involved two stages. In the first stage the current responses were registered under the applied square and sine voltage signals $u_{k}(t)$, governed by formulas (1) and (2), respectively:

$u_{k}(t)=u_{k}(t+T)= \begin{cases}U_{k} & |t| \leq \frac{T}{2} \\ 0 & |t|>\frac{T}{2}\end{cases}$

$T$ - period of the square voltage signal

$u_{k}(t)=U_{k} \cdot \sin (2 \pi f t)$

$f$ - frequency of the sine voltage signal.

Values $U_{k}$ for the square and sine voltage signals were chosen such that the corresponding steady-state current levels $I_{k}$ should be equal to 1,3 and $5 \mathrm{~A}$. The period $T$ of the square voltage signal was $1 \mathrm{~s}$ and frequency $f$ of the sine voltage signal $u_{k}(t)$ was varied in the range $(0.1,100) \mathrm{Hz}$ with a step of $0.1 \mathrm{~Hz}$. Signals were registered for $10 \mathrm{~s}$.

Current responses of the control coil are graphed as time histories (see Fig. 4-6) and frequency characteristics expressing the magnitude of transfer admittance $|Y|$ in the function of frequency, governed by formula (3).

$\left|Y_{k}(f)\right|=20 \log \left(\frac{i_{k}^{R M S}}{u_{k}^{R M S}}\right)=20 \log \left(\frac{\sqrt{\frac{1}{t} \int_{0}^{t} i_{k}^{2}(t) d t}}{\sqrt{\frac{1}{t} \int_{0}^{t} u_{k}^{2}(t) d t}}\right)$

$u_{k}^{R M S}, i_{k}^{R M S}-\mathrm{rms}$ values of voltage and current.

In the second stage force responses were obtained under the triangular and sine signals of piston displacement. Under the triangular excitations, the piston in its back and forth positions moved at the constant speed 150, 100, 50 and $10 \mathrm{~mm} / \mathrm{s}$, respectively. The amplitude $X_{m}$ of the applied excitation was 75 , 25 and $5 \mathrm{~mm}$. Frequencies $f$ of the triangular input related to relevant amplitudes and velocities are summarised in Tab. 1. Amplitudes and frequencies registered under the sine excitations were identical as those under triangular inputs.

Tab. 1. Frequencies of the applied triangular excitation

\begin{tabular}{|c|l|l|l|}
\hline Amplitude $X_{m}$ & \multicolumn{1}{|c|}{$75 \mathrm{~mm}$} & \multicolumn{1}{|c|}{$25 \mathrm{~mm}$} & \multicolumn{1}{|c|}{$5 \mathrm{~mm}$} \\
\hline $150 \mathrm{~mm} / \mathrm{s}$ & $f=0.5 \mathrm{~Hz}$ & $f=1.5 \mathrm{~Hz}$ & $f=7.5 \mathrm{~Hz}$ \\
\hline $100 \mathrm{~mm} / \mathrm{s}$ & $f=0.33 \mathrm{~Hz}$ & $f=1 \mathrm{~Hz}$ & $f=5 \mathrm{~Hz}$ \\
\hline $50 \mathrm{~mm} / \mathrm{s}$ & $f=0.16 \mathrm{~Hz}$ & $f=0.5 \mathrm{~Hz}$ & $f=2.5 \mathrm{~Hz}$ \\
\hline $10 \mathrm{~mm} / \mathrm{s}$ & $f=0.033 \mathrm{~Hz}$ & $f=0.1 \mathrm{~Hz}$ & $f=0.5 \mathrm{~Hz}$ \\
\hline
\end{tabular}

\section{RESULTS AND DISCUSSION}

\subsection{Current responses}

Fig. 4 shows the current step responses $i_{k}(t)$ registered under the applied square voltage input $u_{k}(t)$ within one period. On that basis the resistance of the control coil was established $(R=1.18$ 
$\Omega)$. Fig. 5 and 6 shows the current responses $i_{k}(t)$ under the rising and trailing edge of the voltage signal $u_{k}(t)$ for the voltage and current modes of the amplifier operation.

Tab. 2 summarises the time constants $T_{a u}$ and $T_{a d}$ of the control coil obtained for the rising and trailing edge and for two operation modes of the amplifier. The time constant $T_{\text {а }}$ is defined as the time required to reach the $90 \%$ of the steady value of current $l_{k}$, whilst $T_{a d}$ is expressed as $10 \%$ of $l_{k}$.

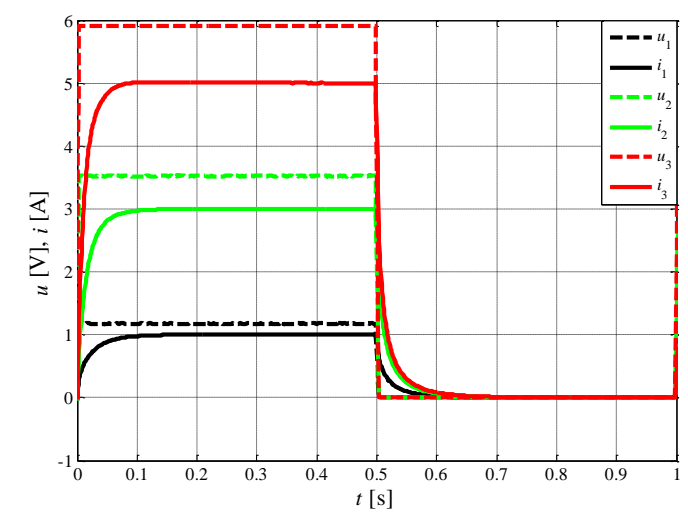

Fig. 4. Current response to a step variation of voltage

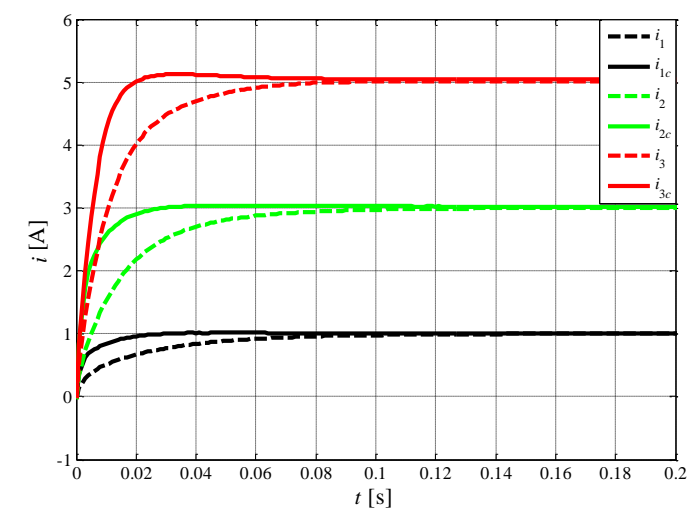

Fig. 5. Current response to a step variation of voltage - rising edge

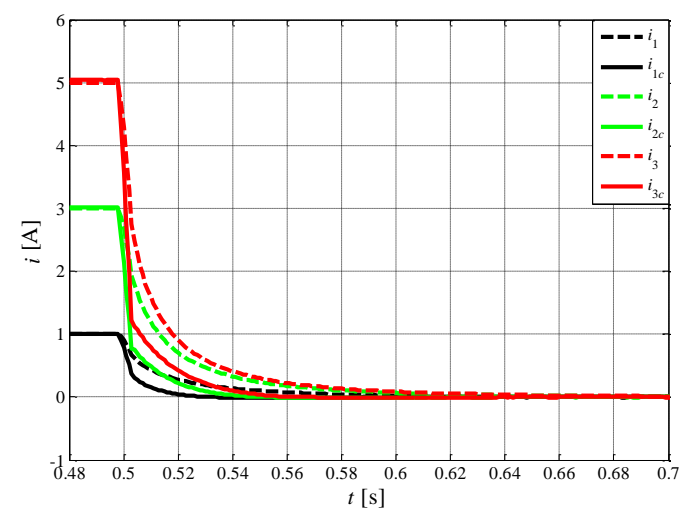

Fig. 6. Current response to a step variation of voltage - trailing edge

In the voltage mode, the time constants depend solely on properties of the control coil integrated in the shock absorber piston. As shown in Tab. 2, the higher the steady state value of current $l_{k}$, the lower the time constants $T_{a u}$ and $T_{a d}$, and in this mode of amplifier operation they do not differ by more than $15 \%$. In the current mode, the values of time constants $T_{a u}$ and $T_{a d}$ are 2-3.8 fold lower than those registered in the voltage mode. Fig. 7 plots the transfer admittance magnitude $\mid Y$ of the control coil in the voltage mode. In the frequency range $(0.1,1) \mathrm{Hz}$ the value of $|Y|$ does not change with varied frequency and is equal to $|Y|=1.35 \mathrm{~dB}$. Cut-off frequency values $f_{g}$ for the steady-state current levels $l_{k} 1,3$ and $5 \mathrm{~A}$ are $5.8,6.5$ and $7.1 \mathrm{~Hz}$, respectively. Increasing the current $I_{k}$ causes the cut-off frequency $f_{g}$ to rise, which is confirmed by variability patterns of time constants. The rates of $|Y|$ decrease for frequencies $f>f_{g}$ and for steady-state current levels $l_{k}: 1,3$ and $5 \mathrm{~A}$ they become $9,11.4$ and $12.3 \mathrm{~dB} / \mathrm{dec}$, respectively.

Tab. 2. Time constant of the control coil

\begin{tabular}{|c|c|c|c|c|}
\hline $\begin{array}{c}\text { Steady-state } \\
\text { current level }\end{array}$ & \multicolumn{2}{|c|}{ Voltage mode } & \multicolumn{2}{c|}{ Current mode } \\
\hline $\boldsymbol{I}_{\boldsymbol{k}}$ & $\boldsymbol{T}_{\text {au }}$ & $\boldsymbol{T}_{\text {ad }}$ & $\boldsymbol{T}_{\text {au }}$ & $\boldsymbol{T}_{\text {ad }}$ \\
\hline $1 \mathrm{~A}$ & $54 \mathrm{~ms}$ & $47 \mathrm{~ms}$ & $14 \mathrm{~ms}$ & $14 \mathrm{~ms}$ \\
\hline $3 \mathrm{~A}$ & $40 \mathrm{~ms}$ & $43 \mathrm{~ms}$ & $13 \mathrm{~ms}$ & $16 \mathrm{~ms}$ \\
\hline $5 \mathrm{~A}$ & $31 \mathrm{~ms}$ & $34 \mathrm{~ms}$ & $11 \mathrm{~ms}$ & $17 \mathrm{~ms}$ \\
\hline
\end{tabular}

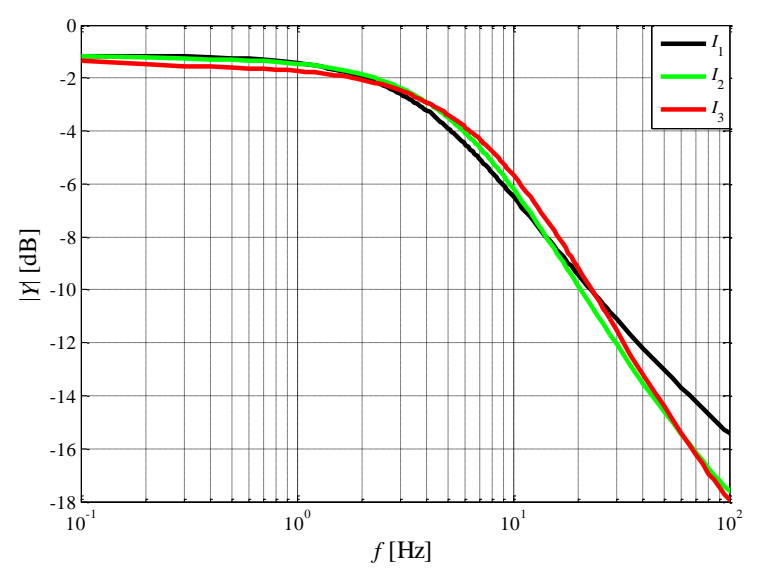

Fig. 7. Transfer admittance magnitude $|Y|$ vs frequency

\subsection{Force responses}

In the second stage the investigations focused on the effects of operating current $I$ variations in the control coil, amplitudes of piston displacement $X_{m}$ and piston velocity $v$ on the magnitude of force generated by the shock absorber.

\section{Effects of operating current}

Fig. 8 and 9 plot the dependence of force $F$ and displacement $x$ under the triangular excitations (constant velocity $v$ of the piston motion in compression and rebound positions: 50 and $150 \mathrm{~mm} / \mathrm{s}$ ), corresponding amplitudes $X_{m}$ : 75 and $25 \mathrm{~mm}$. To facilitate the analysis of results, the range of generated forces $\Delta F$ is defined as the difference of forces registered for the displacement $x=0 \mathrm{~mm}$ in the back and forth cycle of the piston motion. An increase of current $I$ from 0 to $5 \mathrm{~A}$ results in a nearly 14-fold increase of $\Delta F$, irrespective of the displacement amplitude $X_{m}$. The average force value representing the shift of the force-displacement loop is associated with the reaction force of an integrated gas accumulator and is approximately equal to $-400 \mathrm{~N}$.

Fig.10 plots the dependence of dissipated energy $E_{d}$ within one cycle of the piston back-forth motion on the current level $I$. It appears that energy $E_{d}$ tends to increase nonlinearly with increasing current level $I$. For piston motion velocities 150 and $100 \mathrm{~mm} / \mathrm{s}$, the values of $E_{d}$ in the investigated range of current $/$ are similar whilst for $V=50$ 
$\mathrm{mm} / \mathrm{s}$ these values are significantly lower for $>1.5 \mathrm{~A}$, irrespective of the amplitude $X_{m}$.

a)

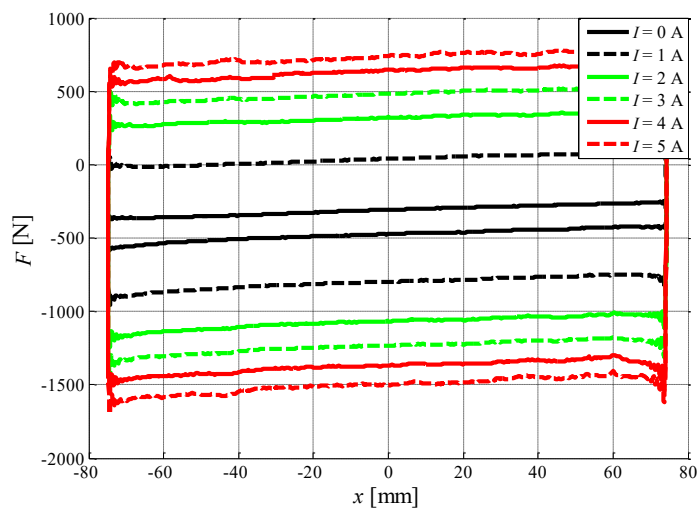

b)

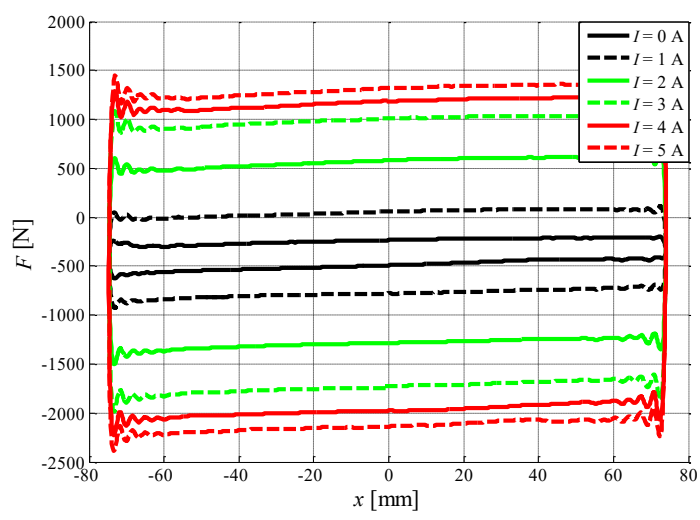

Fig. 8. Force vs displacement: a) $V=50 \mathrm{~mm} / \mathrm{s} ;$ b) $V=150 \mathrm{~mm} / \mathrm{s} ; X_{m}=75 \mathrm{~mm}$

a)

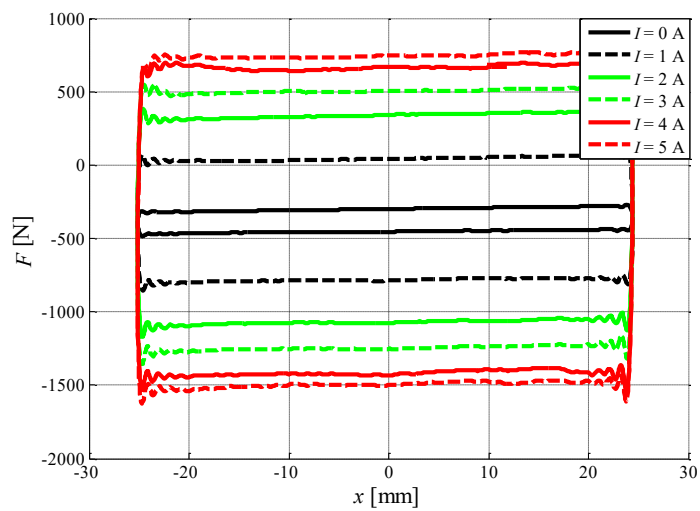

b)

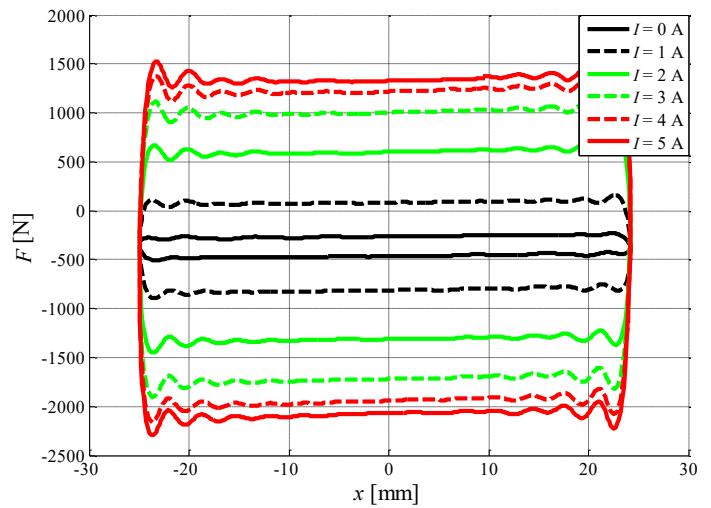

Fig. 9. Force vs displacement: a) $V=50 \mathrm{~mm} / \mathrm{s}$; b) $V=150 \mathrm{~mm} / \mathrm{s} ; X_{m}=25 \mathrm{~mm}$ a)

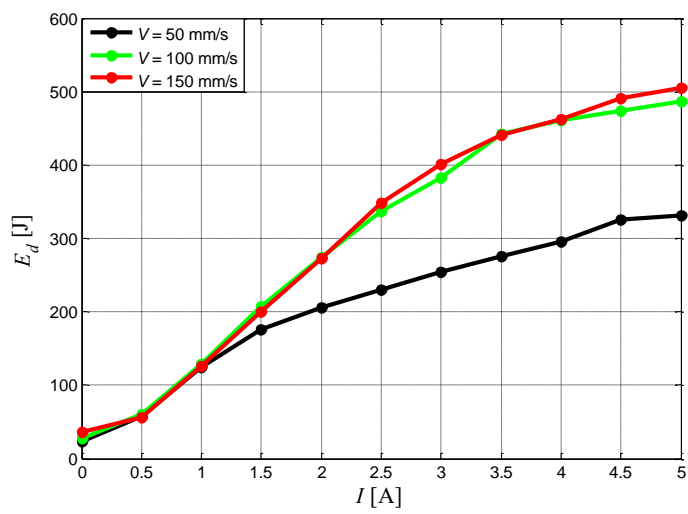

b)

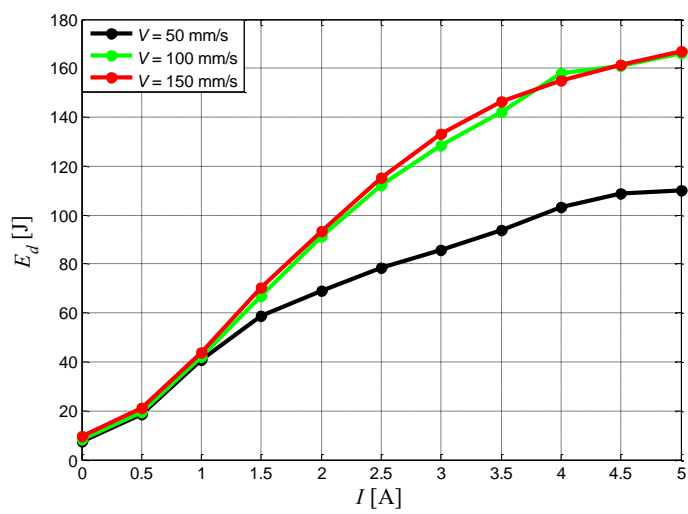

c)

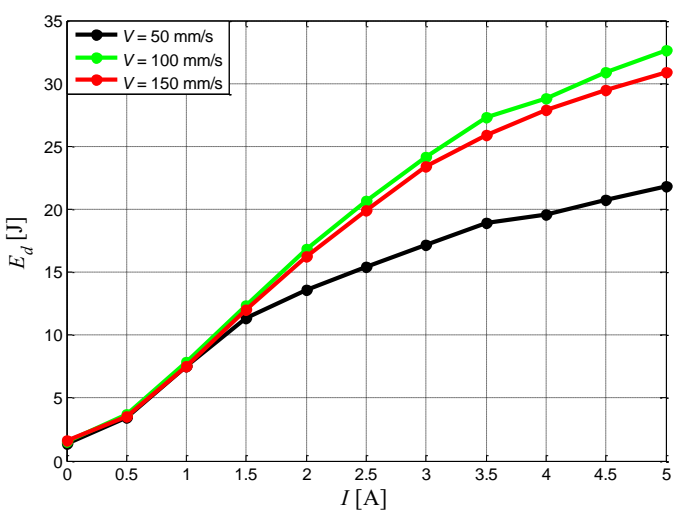

Fig. 10. Dissipated energy vs current: a) $X_{m}=75 \mathrm{~mm}$; b) $X_{m}=25 \mathrm{~mm}$; c) $X_{m}=5 \mathrm{~mm}$

\section{Effects of piston displacement amplitude}

Fig. 11 plots the force $F$ vs piston displacement $x$ dependence for the piston velocity $V=150 \mathrm{~mm} / \mathrm{s}$ and for the current levels $l: 0$, $1,3,5 \mathrm{~A}$. It appears that the piston displacement amplitude $X_{m}$ does not affect the range of generated forces $\Delta F$, irrespective of the actual current level $I$. This observation is confirmed by the linear dependence between dissipated energy $E d$ and displacement amplitude $X_{m}$ (see Fig. 12).

\section{Effects of piston velocity}

Fig. 13 plots the force $F$ under the applied triangular excitation $x$ with amplitude $X_{m}=75 \mathrm{~mm}$ and for the current levels $l: 0,1,3,5$ A. With no power supply to the coil and for velocities $v$ in the interval $(10 ; 100) \mathrm{mm} / \mathrm{s}$, the range of force $\Delta F$ will not significantly change. $\Delta F$ will increase considerably (by nearly $56 \%$ ) when the piston velocity becomes $V=150 \mathrm{~mm} / \mathrm{s}$. For velocity $V=50 \mathrm{~mm} / \mathrm{s}$ (when $l=1 \mathrm{~A}$ ) and $V>100 \mathrm{~mm} / \mathrm{s}$ (when $l=3 \mathrm{~A}$ or $l=5 \mathrm{~A}$ ) there is a slight increase in $\Delta F$. In the velocity range from 10 to $100 \mathrm{~mm} / \mathrm{s}$ (when $l=5 \mathrm{~A}$ ) there is a 8 -fold increase in $\Delta F$. 
a)

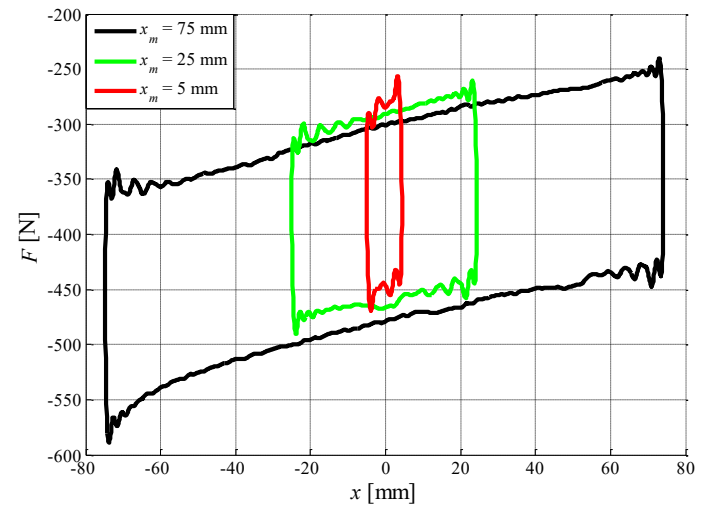

b)

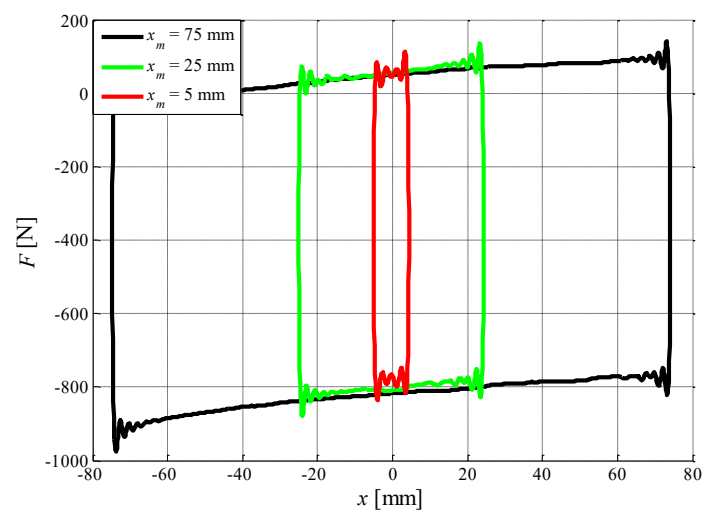

c)

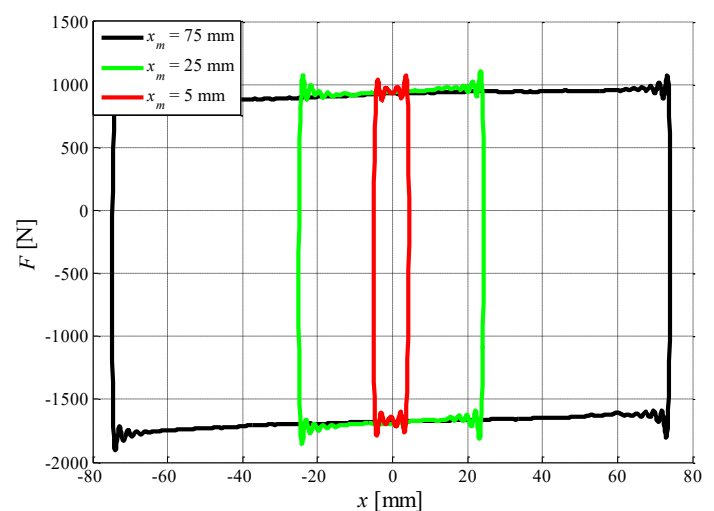

d)

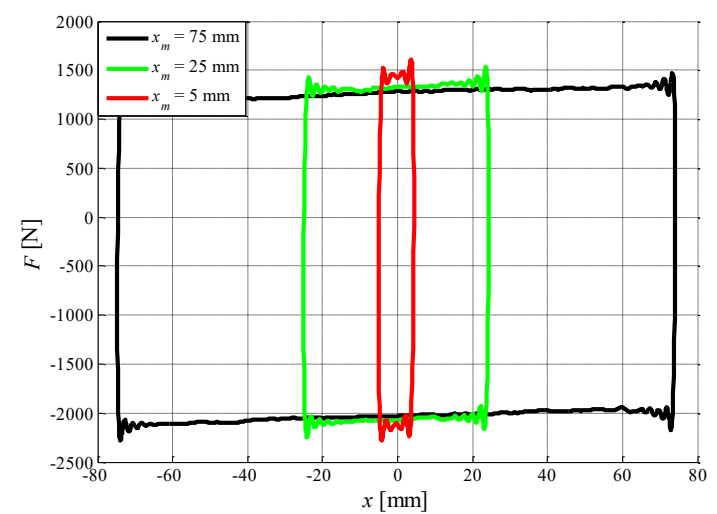

Fig. 11. Force vs displacement: a) $l=0 \mathrm{~A}$, b) $l=1 \mathrm{~A}$; c) $l=3 \mathrm{~A}$; d) $l=5 \mathrm{~A}, V=150 \mathrm{~mm} / \mathrm{s}$

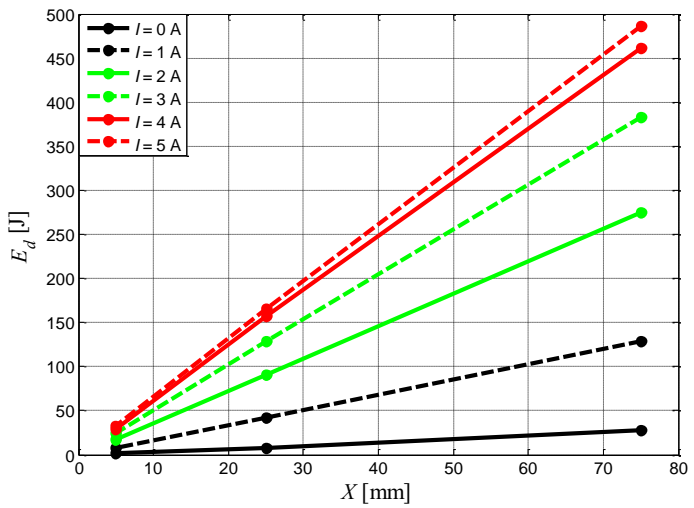

Fig. 12. Dissipated energy vs displacement amplitude; $V=150 \mathrm{~mm} / \mathrm{s}$

a)

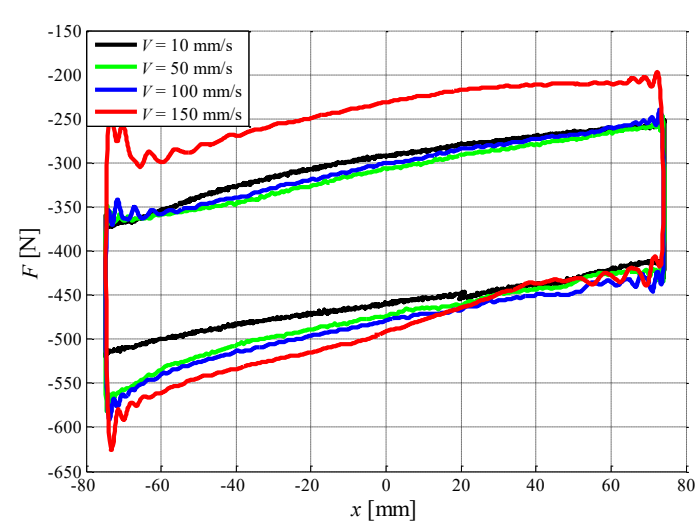

b)

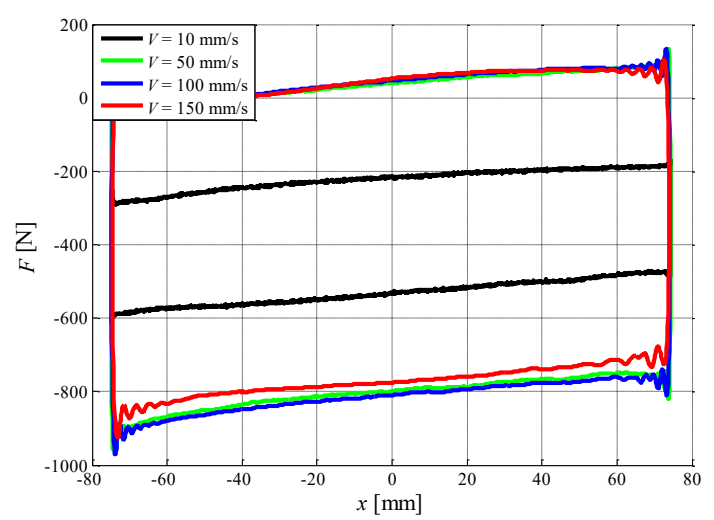

c)

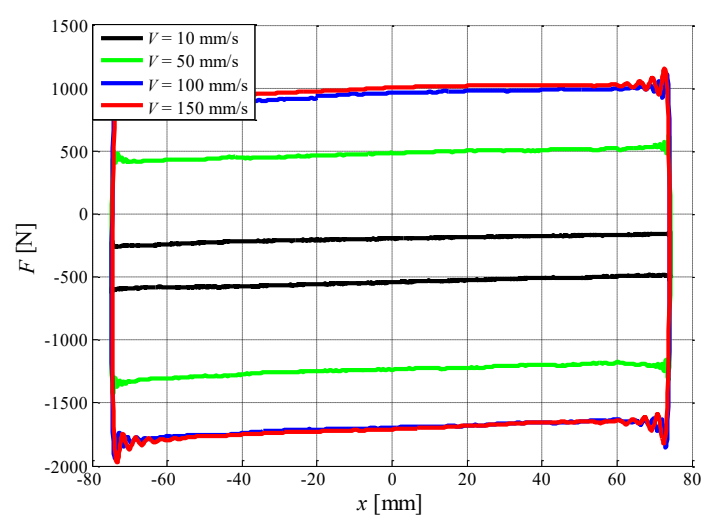


d)

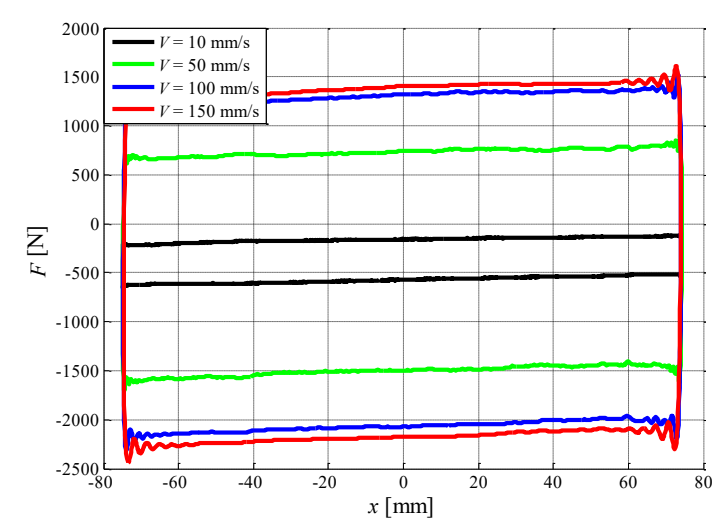

Fig. 13. Force vs displacement: a) $l=0 \mathrm{~A}, \mathrm{~b}) l=1 \mathrm{~A}, \mathrm{c}) l=3 \mathrm{~A}$, d) $l=5 \mathrm{~A}, X_{\mathrm{m}}=75 \mathrm{~mm}$

a)

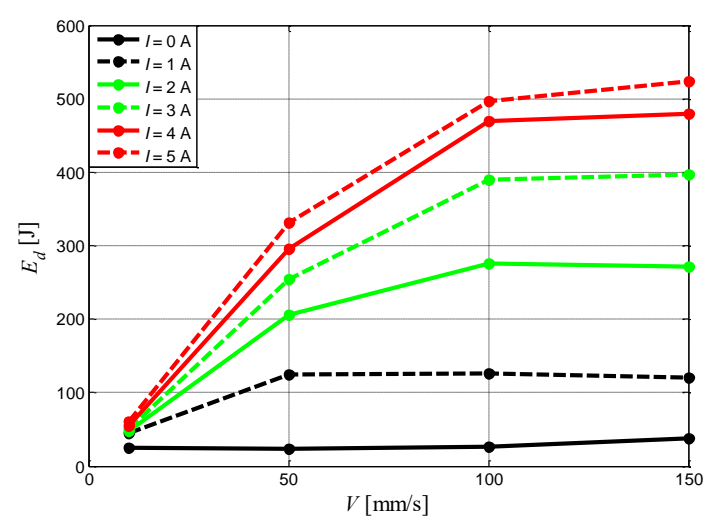

b)

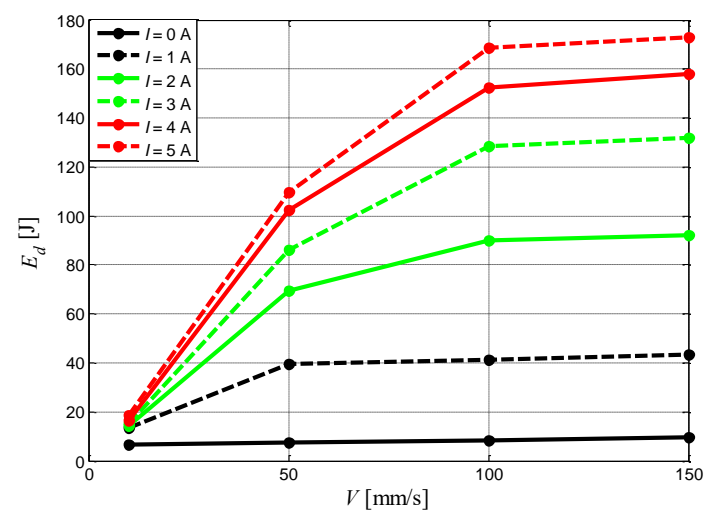

Fig. 14. Dissipated energy vs piston motion velocity: a) $X_{m}=75 \mathrm{~mm}$; b) $X_{m}=25 \mathrm{~mm}$

Fig. 14 plots the relationship between dissipated energy $E_{d}$ and velocity $V$ for varied current levels $I$. With no power supply to the coil, the influence that velocity $v$ has on dissipated energy $E_{d}$ is negligible; when the coil is power-supplied the situation is entirely different. $E_{d}$ tends to grow significantly with velocity when $V=50 \mathrm{~mm} / \mathrm{s}(I \leq 1 \mathrm{~A})$ or $V<100 \mathrm{~mm} / \mathrm{s}(\mid>1 \mathrm{~A})$. Fig. 15 and 16 plot the dependence of $F$ on piston displacement $x$ and of the force $F$ on piston velocity $v$ under the sine excitation with the amplitude $X_{m}=75 \mathrm{~mm}$ and frequency $f=0.333 \mathrm{~Hz}$ (when the maximal velocity equals $150 \mathrm{~mm} / \mathrm{s}$ ), revealing a narrow hysteresis loop.

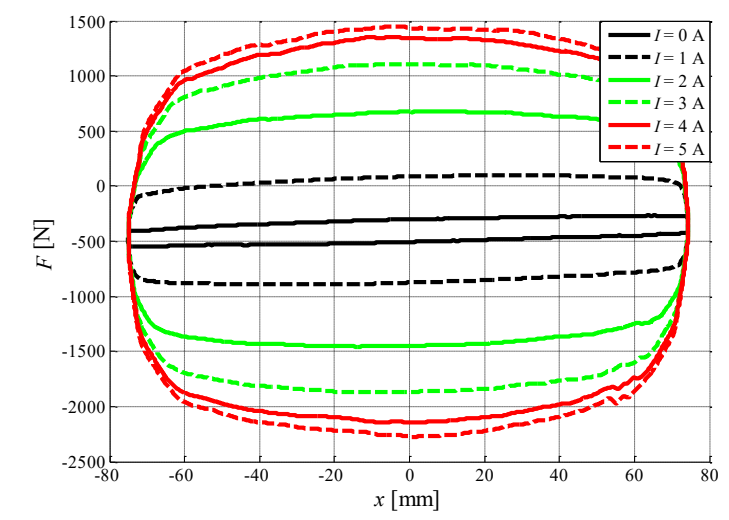

Fig. 15. Force vs displacement under sine excitations

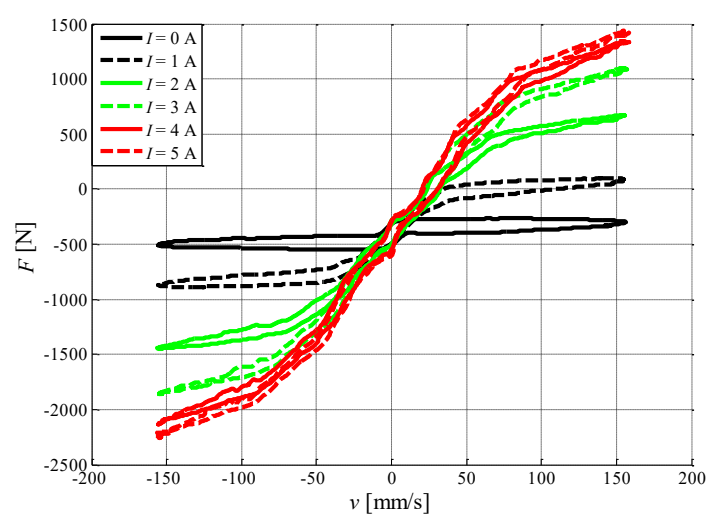

Fig. 16. Force vs velocity under sine excitation

\section{SUMMARY}

This study summarises the experimental testing of an automotive MR shock absorber under the electrical and mechanical excitations. The goal of the experiments was to acquire measurement data of the shock absorber. The main focus is on current and force responses of the device.

The obtained results lead the authors to the following conclusions:

- time constants $T_{a u}$ and $T_{a d}$ derived basing on step responses (for the amplifier operated in the voltage mode) tend to decrease with increased current levels in the control coil,

- this variability patterns of time constants $T_{a u}$ and $T_{a d}$ impact on the frequency characteristics (increasing the current levels leads to an increase of critical frequency $f_{g}$ ),

- current level has also influence on the rate of decrease of $|Y|$ in the frequency characteristics for $f>f_{g}$,

- when current level is increased from 0 to $5 \mathrm{~A}$, the range of force $\Delta F$ generated by the absorber at the piston velocity $V=50 \mathrm{~mm} / \mathrm{s}$ varies from $157 \mathrm{~N}$ to $2200 \mathrm{~N}$, for $V=150 \mathrm{~mm} / \mathrm{s}$ the force ranges from $257 \mathrm{~N}$ to $2457 \mathrm{~N}$,

- major determinants of the force range are the current level $I$ and piston velocity $v$, whilst the effects of amplitude $X_{m}$ are negligible.

The experimental data seems to be sufficient to formulate the design objectives of an energy harvesting device for the investigated shock absorber. The function of the harvester is to convert the energy of mechanical vibrations into electric energy required to power-supply (control) the shock absorber implemented in purpose-built laboratory model of a suspension system with 
energy recuperation capability. As regards the obtained critical frequencies $f_{g}$, one has to bear in mind that the resonance phenomenon in the modeled system ought to occur at frequency $f<5 \mathrm{~Hz}$.

\section{REFERENCES}

1. Choi S.B., Han Y.M. (2012), Magnetorheological Fluid Technology Applications in Vehicle Systems, Padstow, United States: CRC Press Taylor \& Francis Group.

2. Choi S.B., Sung K.G. (2008), Vibration control of magnetorheological damper system subjected to parameter variations, International Journal of Vehicle Design, 45, 94-110.

3. El-Kafafy M., El-Demerdash S., Rabeih A. (2012), Automotive ride comfort control using MR fluid damper, Engineering, 4(4), 179-87.

4. Gołdasz J., Dzierżek S. (2016), Parametric study on the performance of automotive MR shock absorbers, IOP Conf. Series: Materials Science and Engineering, 148, 012004.

5. Gołdasz J., Sapiński B. (2015), Insight into Magnetorheological Shock Absorbers, Springer International Publishing AG Switzerland.

6. Koo J.H., Goncalves F.D., Ahmadian M. (2006), A comprehensive analysis of the time response of MR dampers, Smart Materials and Structures, 15, 351-358.

7. Sapinski B., (2014), Energy harvesting MR linear damper: prototyping and testing, Smart Materials and Structures, 23, 035021.

8. Sapiński B., Jastrzębski Ł., Rosół M. (2012,) Power amplifier supporting MR fluid-based actuators, Proceedings of $13^{\text {th }}$ International Carpathian Control Conference ICCC 2012, 612-616.

9. Sapiński B., Rosół M. (2007), MR damper performance for shock isolation, Journal of Theoretical and Applied Mechanics, 1(45), 133-146.
10. Strecker Z., Mazurek I., Roupec J., Klapka M. (2015), Influence of MR damper response time on semiactive suspension control efficiency, Meccanica, 50, 1949-1959.

11. Strecker Z., Roupec J., Mazurek I., Klapka M. (2015), Limiting factors of the response time of the magnetorheological damper, International Journal of Applied Electromagnetics and Mechanics, 47(2), 541-550.

12. Strecker Z., Roupec J., Mazurek I., Machacek O., Kubik M., Klapka M. (2015), Design of magnetorheological damper with short time response, Journal of Intelligent Material Systems and Structures, Special Issue Article, 1-8.

13. Sung K.G., Choi S.B.(2009) Vibration control of vehicle suspension featuring magnetorheological dampers: road test evaluation, Transactions of the Korean Society for Noise and Vibration Engineering, Vol. 19 (3), 235-242.

14. Wang D.H., Bai X.X. (2013), A magnetorheological damper with an integrated self-powered displacement sensor, Smart Materials and Structures, 22, 075001.

15. Wu G., Feng Z., Zhang G., Hou Z., (2011), Experimental Study on Response Time of Magnetorheological Damper, 2nd International Conference on Artificial Intelligence, Management Science and Electronic Commerce (AIMSEC), 3968-3972.

16. Xinchun G., Yonghu H., Yi R., Hui L., Jinping O., (2015), A novel self-powered MR damper: Theoretical and experimental analysis, Smart Materials and Structures, 24, 105033.

17. http://www.inteco.com.pl/

This work is supported by AGH University of Science and Technology under research program No. 11.11.130.958. 